velocities of the light-quanta. According to the above assumption, the conservation laws should not apply for them, and the present comprehensive theory of them, the so-called quantum electrodynamics, must be given up. There exists, however, a primitive theory of radiation in quantum mechanics, namely, the theory which treats the electro-magnetic field classically as an external perturbing force, and this theory may be retained. This theory gives information about the probability of atoms and electrons making specified quantum jumps under the influence of radiation, but gives no information at all about the reaction of the atoms and electrons on the-radiation, and is thus equally consistent with the conservation laws and with the B.K.S. assumptions. This primitive theory of radiation gives no spontaneous emission, but by supplementing it with Einstein's laws of radiation and the B.K.S. assumptions, we can get a fairly complete account of all the elementary radiation phenomena, an account which is in satisfactory agreement with experiment and which is unsatisfactory only because of the lack of unity of its basic assumptions.

In retaining the non-relativistic quantum mechanics and the primitive theory of radiation with unquantised fields, we retain almost all the valuable part of present-day quantum theory. We may include in what we retain the theory of the spinning electron moving in a given electromagnetic field, and the Klein-Nishina formula. The only important part that we give up is quantum electrodynamics. Since, however, the only purpose of quantum electrodynamics, apart from providing a unification of the assumptions of radiation theory, is to account for just such coincidences as are now disproved by Shankland's experiments, we may give it up without regretsin fact, on account of its extreme complexity, most physicists will be very glad to see the end of it.

\footnotetext{
${ }^{1}$ Phil. Mag., 47, 785 (1924), or Z. Phys., 24, 69 (1924).

Z. Phys., 32, 639 (1925).

4 Phys. Rev., 49, 8 (1936). See Nature, 137, 241 (1936).
}

\title{
Stephen Gray: The First Copley Medallist
}

$\mathrm{O}^{\mathrm{N}}$ either February 15 or February 25, 1736, two hundred years ago, Stephen Gray, one of the earliest British electricians, died at the age of eighty-three years in Charterhouse, London, of which he had been an inmate for seventeen years. He had been nominated as a Brother in 1718 by George, Prince of Wales, but the entry in the records relating to his admission runs: "Stephen Gray for ye Prince, John Gwynn for ye Archbishop, John Cox for Earl Cowper and John Allen for ye Duke of Buckingham sworn at ye hospital before a Committee 24 June 1719."

Gray was then about sixty-six years of age, and though it is known that for a long time be had been devoted to physical science and astronomy, it is for the experiments he made in his room and in the courts of Charterhouse when he was over seventy that he will always be remembered. There is a short notice of him by James Burnley in the "Dictionary of National Biography" and the Philosophical Transactions contain a number of his papers, but the best account of his activities was given in a lecture delivered in the Great Hall, Charterhouse, by Dr. (afterwards Sir) Benjamin Ward Richardson (1828-96) on January 22, 1874, a report of which appeared in NATURE a week later.

Dr. Richardson had evidently studied Gray's papers in the Philosophical Transactions, and during the lecture he repeated many of Gray's experiments. Gray apparently belonged to Kent and, said Dr. Richardson, he is first discovered at Canterbury in 1692 making observations of a mock sun on February 6. Four years later he was making a water microscope, and in 1698 a microscope with a micrometer for measuring accurately the height of the mercury in a barometer. He studied the fossils of Reculver Cliff in Kent, made observations of sunspots and watched the solar eclipse of 1706, having at Canterbury a well-equipped observatory.

After 1706 Gray is lost sight of until he is recommended as a pensioner for Charterhouse. His first electrical paper in the Philosophical Transactions, entitled "An Account of Some New Electrical Experiments", appeared in 1720, and for the next ten or twelve years he devoted himself entirely to electricity. His apparatus consisted of such things as feathers, hair, silk, wool, soap bubbles, resin slabs, beeswax and cubes of oak; and he made observations on the electricity of the human body. Perhaps his greatest achievement was transmitting electricity through long lengths of pack-threads. In the grounds of the mansion of his friend Granville Wheler, Otterden House, Faversham, on July 14, 1729, he transmitted electricity through a pack-thread line $650 \mathrm{ft}$. long suspended by silk from poles, thus anticipating 
by nearly a century the experiments of Sir Francis Ronalds at Hammersmith.

Gray's experiments had considerable influence on his contemporaries and on none more than on the French experimentalist Charles Francois du Fay (1698-1739).

Three events of interest marked the closing years of Gray's life. On November 23, 1731, when the Prince of Wales and the Duke of Lorraine visited the Royal Society, then housed in Crane Court and presided over by Sir Hans Sloane, among the experiments shown the distinguished visitors were those of "Mr. Gray, which succeeded, notwithstanding the largeness of the company", and about the same time Gray became the first beneficiary under the bequest of Sir Godfrey Copley, who when he died in 1709 left $£ 100$ to the
Royal Society "to be laid out in experiments or otherwise for the benefit thereof as they shall direct and appoint". The fund was not used for a medal until 1736, but Weld in his list of "Awards of the Copley Medal" places Gray's name at the head. The third event was the ad. mission of Gray in 1732 as a fellow of the Royal Society. That he had not been admitted before may perhaps have been due to pecuniary circum. stances and his position as a pensioner of Charterhouse; but, however this may be, it does not lessen our debt to him as a pioneer in electrical science, and one who predicted that what he was doing in minimus would, some day, be so extended that electrical phenomena would be made to resemble those of thunder and lightning.

\section{Science in the Service of the State}

$\mathrm{T}$ HE growing number of separate departmental reports issued by the research boards and stations of the Department of Scientific and Industrial Research, among which were included last year for the first time those of the Road Research Board and the Chemical Research Laboratory, enhances, rather than diminishes, the importance of the Annual Report of the Department. No other document gives such a comprehensive picture of the way in which science has been mobilised in the service of every aspect of our national needs, whether of the great departments of State, industry, municipal services or of the everyday wants of the home. The twentieth Annual Report of the Department* issued on December 30 covers the period October 1, 1934September 30, 1935, and contains the brief report of the Privy Council Committee, signed by the Right Hon. J. Ramsay MacDonald, Lord President of the Council, the longer report of the Advisory Council over Lord Rutherford's signature and summaries of the work of the National Physical Laboratory, the Chemical Research Laboratory, the various research associations and research boards or committees.

The gross expenditure of the Department in 1934-35 was $£ 719,276$ or $£ 549,781$ net, as against $\mathfrak{\$ 4 7 6 , 8 9 7}$ net in $\mathbf{1 9 3 3 - 3 4}$. In this, the National Physical Laboratory, with $£ 219,039$ gross or $£ 122,847$ net, is as usual the largest single item of expenditure; but the gross figure includes the cost

* Department of Scientific and Industrial Research. Twentieth Annual Report for the Year 1934-35. Pp. iv +185. (London: H.M. Stationery Office, 1935.) 38 , net. of work at the Laboratory for the Food Investiga. tion Board, the Radio Research Board, the Road Research Board and other research boards of the Department. Expenditure on the Chemical Research Laboratory was $£ 21,722$ net, on food investigation $\mathfrak{£ 3}, 539$, forest products research $£ 39,408$, and on fuel research $£ 83,984$, all net. Against gross expenditure of $£ 69,723$ on building and road research and $£ 11,769$ on water pollution research, receipts amounted to $£ 35,906$ and $£ 6,638$ respectively, while a further sum of $£ 10,847$ was received against expenditure on food investigation. The net expenditure on the Geological Survey and Museum was $£ 65,137$ and the centenary of the Geological Survey, the senior organisation of the Department, coincided with the opening in July of the new buildings in South Kensington for the headquarters of the Survey and the Museum of Practical Geology.

The work of the Geological Survey is funda. mental for all important schemes of civil engineering, mining and water supply, and is of direct interest to agriculture. It is the senior geological survey of the world, and no British scientific institution has more frequently served as a model for similar establishments both in the Empire and in foreign countries. In addition to re-surveying coalfields of Yorkshire, Lancashire, Cumberland, Northumberland, Forest of Dean, Forest of Wyre, Fifeshire, Dumfriesshire, Stirlingshire, Ayrshire and Lanarkshire, an exceptional number of inquiries on water-supply and inspections of borings for water have been dealt with as 